\title{
Selective anion transport mediated by strap-extended calixpyrroles
}

\author{
Harriet J. Clarke ${ }^{a}$, Xin Wu ${ }^{a, b}$, Mark E. Light ${ }^{a}$, and Philip A. Gale ${ }^{\star a, b}$ \\ ${ }^{a}$ Chemistry, University of Southampton, Southampton SO17 1BJ, UK

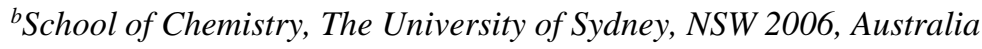 \\ Received date (to be automatically inserted after your manuscript is submitted) \\ Accepted date (to be automatically inserted after your manuscript is accepted)
}

Dedicated to Professor Atsuhiro Osuka on the occasion of his $65^{\text {th }}$ birthday.

\begin{abstract}
Synthetic anion receptors that facilitate transmembrane chloride transport are of interest as potential therapeutic agents for cancer and cystic fibrosis. Transporters selective for chloride over protons are desired for therapeutic applications to avoid autophagy inhibition and cytotoxicity. Examples of such compounds are rare because the majority of anion transporters can interact with the carboxylate head groups of fatty acids leading to proton leakage. In this paper, we report the synthesis, anion binding and transmembrane anion transport properties of two novel bis-triazole-functionalized calixpyrroles with extended straps, and compare them to previously reported shorter-strap analogues known to exhibit high $\mathrm{Cl}^{-}>\mathrm{H}^{+}$selectivity. We demonstrate improved chloride transport activities of the strap-extended compounds that likely benefits from increased lipophilicity, and reduced $\mathrm{Cl}^{-}>\mathrm{H}^{+}$selectivity due to the larger anion binding cavities facilitating interaction with fatty acids. The results are instructive for future design of ideal anion transporters with potent activity and high selectivity against proton leakage.
\end{abstract}

KEYWORDS: Anion coordination chemistry; Transmembrane anion transporters; Chloride transport; Calixpyrrole.

*Correspondence to: Philip A. Gale, tel: +6129351 4813, fax: +6129351 3329, email: philip.gale@sydney.edu.au

* SPP member. 


\section{INTRODUCTION}

Synthetic small molecules that bind anions and facilitate transmembrane anion transport have attracted significant research effort recently due to their potential application in the treatment of cancer and ion-channel diseases such as cystic fibrosis.[1] Several classes of synthetic anion transporters including prodigiosin analogues,[2] tambjamines,[3] tripodal tris(thioureas),[4] bisureas[5] and squaramides[6] are known to perform potent $\mathrm{H}^{+} / \mathrm{Cl}^{-}$cotransport mimicking the natural product prodigiosin[7] and induce de-acidification of lysosomal $\mathrm{pH}$ leading to autophagy inhibition[8] and apoptosis induction.[4,5] Although these compounds are potential anti-cancer agents, other types of compounds that soley facilitate $\mathrm{Cl}^{-}$uniport without comcomitant transport of $\mathrm{H}^{+}$are required for channel-replacement therapy applications where $\mathrm{pH}$ gradient disruption and cytotoxicity are undesired side effects.[9] The design of such $\mathrm{Cl}^{-}-$ selective uniporters has proved to be highly challenging because most anion transporters can facilitate $\mathrm{H}^{+}$transport via deprotonation (in the cases of compounds containing highly acidic hydrogen bond donors)[9] or by interacting with the carboxylate headgroup of fatty acids leading to an indirect $\mathrm{H}^{+}$transport pahthway via fatty acid flip-flop.[10] In our efforts towards making ideally $\mathrm{Cl}^{-}$-selective uniporters, we have identified promising compounds including tripodal tristhioureas with alkyl substituents (e.g. 1)[9,11] and strapped calixpyrroles containing additional hydrogen bonding sites in the strap (e.g. compounds 2-4) (Figure 1).[12] In particular, compound 1[9] and an amide-stapped calixpyrrole[8a] have been subject to biological studies where the $\mathrm{Cl}^{-}>\mathrm{H}^{+}$selectivity determined in vesicles assays has been correlated with weak activity in increasing lysosomal $\mathrm{pH}$ and disrupting autophagy. The tripodal compounds are potent $\mathrm{Cl}^{-}$uniporters and highly selective against $\mathrm{H}^{+}$transport in the absence of fatty acids, but show substantially reduced selectivity when fatty acids are present in significant amounts due to their favorable interaction with carboxylates.[10,11] In contrast, the strapped calixpyrroles (compounds 2-4) are $\mathrm{Cl}^{-}>\mathrm{H}^{+}$selective transporters that maintain the high selectivity even in the presence of fatty acids.[12] This is presumably due to the geometry of the strapped calixpyrroles allowing encapsulation of speherical halide ions by multiple hydrogen bonds from many spatial directions, whereas the Y-shape carboxylates do not allow maximum interaction with the three dimentional hydrogen bond donor arrays of these compounds.[13] The strapped calixpyrroles, however, are $>200$ times less active than the tripodal tristhiourea $\mathbf{1}$ in $\mathrm{Cl}^{-}$uniport.[12] To better understand the selectivity and seek further improvements for the strapped calixpyrroles, we have decided to extend the size of the strapped cavity and synthesized novel anion receptors $\mathbf{5}$ and $\mathbf{6}$. In the current study, we report the anion binding and transport properties of the new strapped calixpyrroles $\mathbf{5}$ and $\mathbf{6}$ in comparison to the previous analogues 2-4.
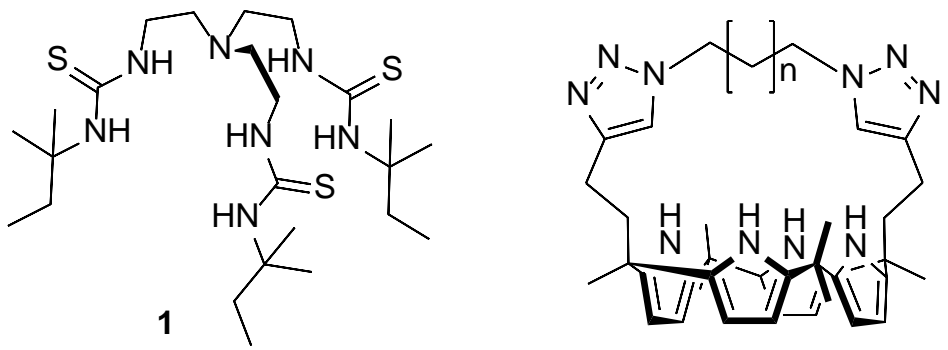

$2 n=1$
$3 n=2$
$4 n=3$
$5 n=4$
$6 n=6$

Fig. 1. Structures of tripodal tristhiourea $\mathbf{1}$ and strapped calixpyrroles 2-6.

\section{EXPERIMENTAL,}

\section{Synthesis and vesicle preparation}

See Supplemental Materials for full details of compound synthesis and vesicle preparation. 


\section{ISE assay for $\mathrm{Cl}^{-}$uniport and $\mathrm{H}^{+} / \mathrm{Cl}^{-}$symport}

POPC vesicles (mean diameter $200 \mathrm{~nm}$ ) were prepared containing an internal solution of $\mathrm{KCl}$ (300 mM) buffered to pH 7.2 with $10 \mathrm{mM}$ HEPES, suspended in an external solution of potassium D-gluconate (300 mM) buffered to pH 7.2 with $10 \mathrm{mM}$ HEPES. Test solutions were made in $5 \mathrm{~mL}$ vials at a lipid concentration of $1 \mathrm{mM}$. In general, a $5 \mu \mathrm{L}$ DMSO solution of valinomycin (for testing $\mathrm{Cl}^{-}$uniport, $1 \mu \mathrm{M}$ or $0.1 \mathrm{~mol} \%$ ) or monensin (for testing $\mathrm{H}^{+} / \mathrm{Cl}^{-}$symport, 1 $\mu \mathrm{M}$ or $0.1 \mathrm{~mol} \%$ ) was added at $\mathrm{t}=0 \mathrm{~s}$ and at $\mathrm{t}=30 \mathrm{~s}$, a $10 \mu \mathrm{L}$ DMSO solution of the compound was added to initiate the transport and the anion efflux was monitored using a chloride or fluoride selective electrode. After $t=300 \mathrm{~s}$ the vesicles were lysed using Triton $\mathrm{X}-100$ detergent and after $\mathrm{t}=420 \mathrm{~s}$ a final anion efflux reading was taken as $100 \%$ for calibration purposes.

\section{HPTS assay}

POPC vesicles (mean diameter $200 \mathrm{~nm}$ ) were prepared containing an internal solution of HPTS (1 mM) and NMDG$\mathrm{Cl}$ (100 mM) buffered to pH 7 with $10 \mathrm{mM}$ HEPES, suspended in an external solution of NMDG-Cl (100 mM) buffered to $\mathrm{pH} 7$ with $10 \mathrm{mM}$ HEPES. Test solutions were made to $2.5 \mathrm{~mL}$ in cuvettes at a lipid concentration of $0.1 \mathrm{mM}$. In general, a $5 \mu \mathrm{L}$ DMSO solution of the compound was added followed by a base pulse (NMDG $5 \mathrm{mM}$ ) at $\mathrm{t}=0 \mathrm{~s}$ to initiate the experiment. The fluorescence ratio acidic and basic forms of HPTS ( $\lambda_{\mathrm{ex}}=403 \mathrm{~nm}$ and $460 \mathrm{~nm}$ respectively) were measured using a fluorimeter. After $\mathrm{t}=200 \mathrm{~s}$ the vesicles were lysed with Triton X-100 detergent to fully dissipate the $\mathrm{pH}$ gradient for calibration purposes. If the experiment involves the addition of gramicidin $\mathrm{D}(0.1 \mu \mathrm{M}$ or mol\%) or oleic acid ( $2 \mu \mathrm{M}$ or mol\%) these are added prior to the addition of the compound.

\section{RESULTS AND DISCUSSION}

\section{Synthesis}

Compounds 5 and $\mathbf{6}$ were synthesised following the literature procedure outlined by Yano et al.[12b] as schematically shown in Fig. 2.
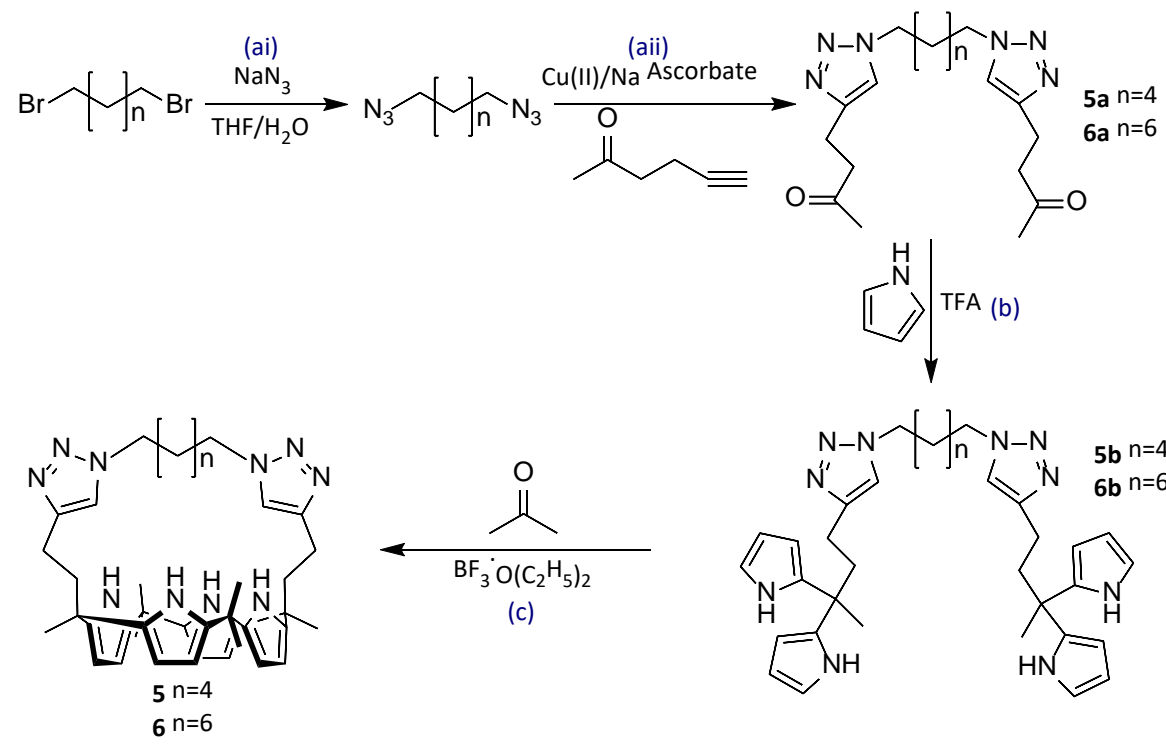

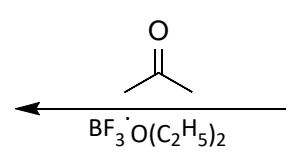

(c)

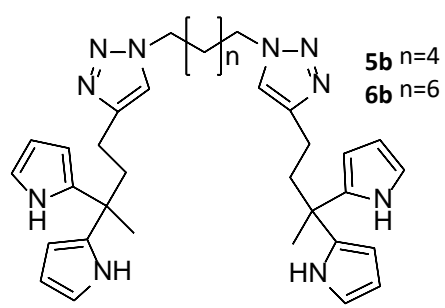

Fig. 2. Synthesis of the extended strapped calix[4]pyrroles 5 and $\mathbf{6}$.

\section{Anion Binding Studies}


Proton NMR titration studies were conducted in DMSO- $d_{6}: \mathrm{H}_{2} \mathrm{O}(99.5: 0.5, \mathrm{v} / \mathrm{v})$ with tetrabutylammonium acetate, fluoride, chloride, bromide, iodide (TBAOAc, TBAF, TBACl, TBABr and TBAI) for 2-6 if not previously reported (Fig. S5-S22, Supplemental Materials). As seen previously[12] slow exchange was observed on the NMR timescale for most compounds 2-6 with TBAOAc, TBAF, TBACl and TBABr. For illustration, the NMR spectra stack plot and binding curve of compound 5 with $\mathrm{TBACl}$ are shown in Fig. 3. The pyrrolic $\mathrm{NH}$ and triazole $\mathrm{CH}$ underwent downfield shifts by 1.5 and $0.8 \mathrm{ppm}$, respectively, upon binding of $\mathrm{Cl}^{-}$, indicating the formation of strong $\mathrm{NH}^{\cdots} \mathrm{Cl}^{-}$and $\mathrm{CH}^{\cdots} \mathrm{Cl}^{-}$ hydrogen bonds consistent with crystallgraphic analysis of $\mathrm{Cl}^{-}$complexes (vide infra). The pyrrolic $\mathrm{CH}$ signals shifted upfield by $0.2 \mathrm{ppm}$ because of increased electron density of the pyrole ring upon $\mathrm{Cl}^{-}$binding. The species ratio determined by intergration of pyrrolic NH signals from the free and bound species demonstrate a strong binding profile with $\sim 100 \%$ saturation at 1 equivalent of $\mathrm{TBACl}$, which has prevented calculation of the binding constant. Similar strong binding isotherms were observed for titrations of 2-6 with TBAF, TBACl, TBABr and TBAOAc, and in all these cases the binding constants are estimated to be $>10^{4} \mathrm{M}^{-1}$. In contrast, weak interactions were found for titrations with TBAI and the binding constants were calculated for $\mathbf{5}$ and $\mathbf{6}$ using global fitting analysis with bindfit,[14] giving a $K_{a}$ value of $11 \mathrm{M}^{-1}$ for both compounds (Figs S16 and S21). As expected, the larger more charge diffuse iodide anion interacts weakly with the hydrogen-bond donors.
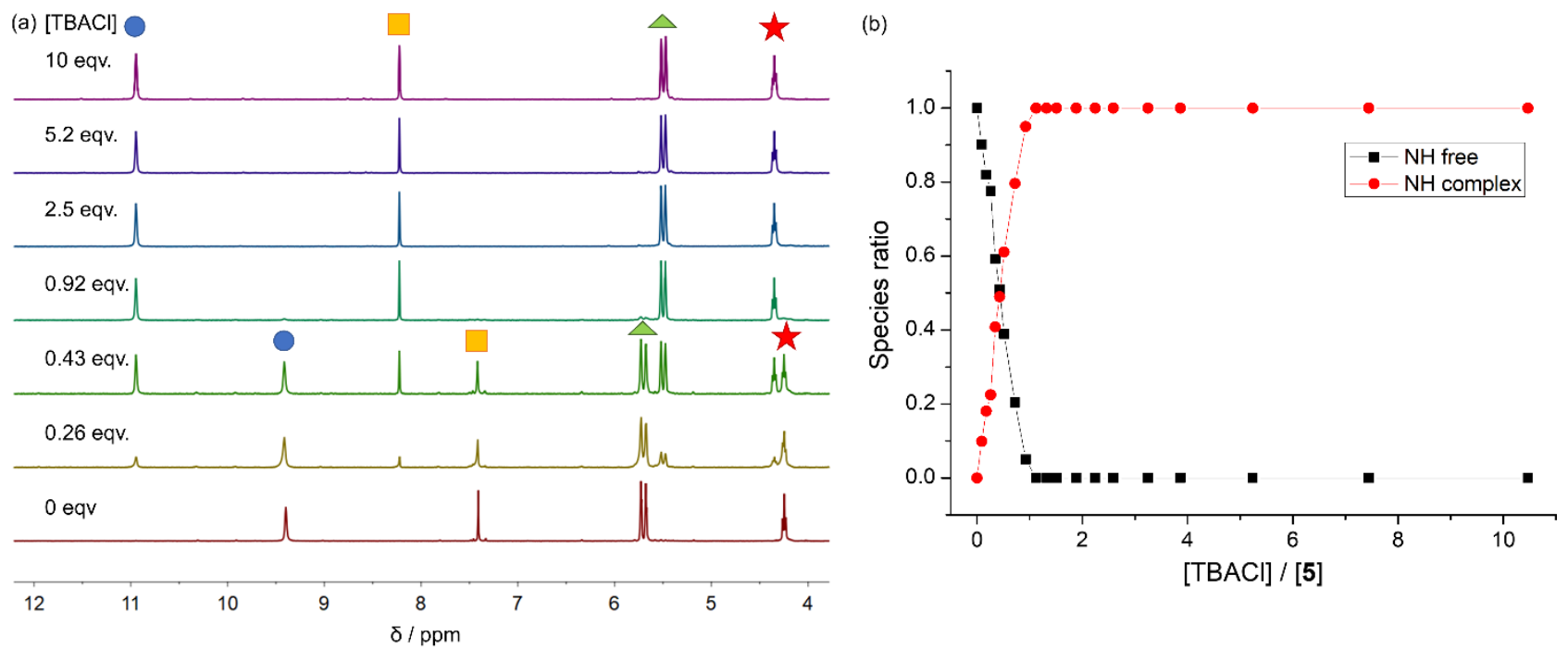

Fig. 3. (a) Stack plots for compound $5{ }^{1} \mathrm{H}$ NMR titration with TBACl in DMSO- $d_{6}: \mathrm{H}_{2} \mathrm{O}(99.5: 0.5$, v/v). Blue circle follows the pyrrole $\mathrm{NH}$ signal, orange square follows the triazole $\mathrm{CH}$ signal, green triangle follows the pyrrole $\mathrm{CHs}$ signal and the red star follows an alkyl $\mathrm{CH}_{2}$. (b) Species ratio for the free $\mathbf{5}$ and $\mathbf{5}-\mathrm{Cl}^{-}$complex, determined by intergration of pyrrole $\mathrm{NH}$ signals.

\section{Solid state analysis}

Compounds $\mathbf{5}$ and $\mathbf{6}$ were crystallized with TBACl by slow diffusion of petroleum spirits into a DCM solution of $\mathbf{5}$ with TBACl (5 equiv) and slow evaporation from a DMSO solution of 6 and excess TBACl, respectively. The solid state structures of these complexes (Fig. 4) show the anion bound within the strapped cavity of the calix[4]pyrrole compound stablized by ten hydrogen bonds that involve four pyrrolic $\mathrm{NH}$, two triazolium $\mathrm{CH}$, and four methylene $\mathrm{CH}$ hydrogen bond donors. Compound 5 and $\mathbf{6}$ shows $\mathrm{N}^{\cdots} \mathrm{Cl}^{-}$distances that range from 3.31-3.33 $\AA$ and 3.27-3.38 $\AA$ respectively. Compound 5 displays triazole $\mathrm{C}^{\cdots} \mathrm{Cl}^{-}$distances of 3.72 and $3.77 \AA$, while longer $\mathrm{C}^{\cdots} \mathrm{Cl}^{-}$distances $(3.97$ and $4.00 \AA$ ) were found for the triazoles of $\mathbf{6}$. Similarly to previously reported crystal structures of shorter strapped analogues, these structures demonstrate favorable interactions with $\mathrm{Cl}^{-}$that features multiple hydrogen bonds from many spatial directions to maximize the contact with the bound $\mathrm{Cl}^{-}$ion. Such a binding mode is assumed to confer preference for spherical halide ions over non-spherical anions such as carboxylates. 
(a)

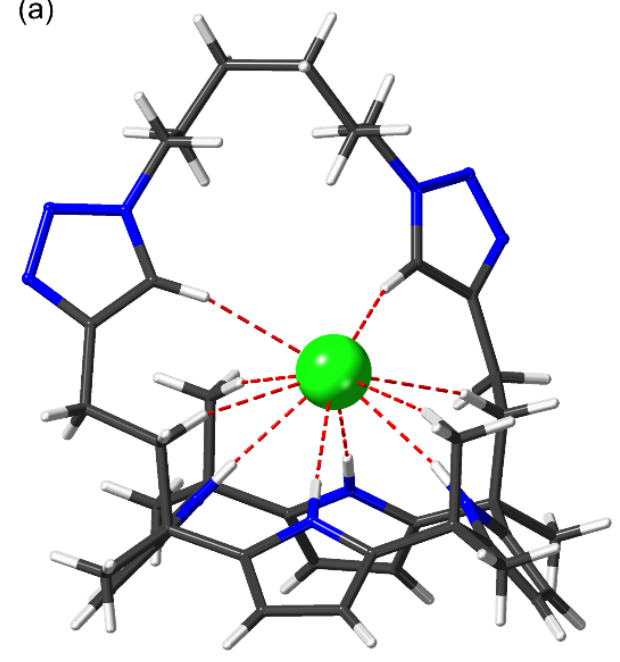

(b)

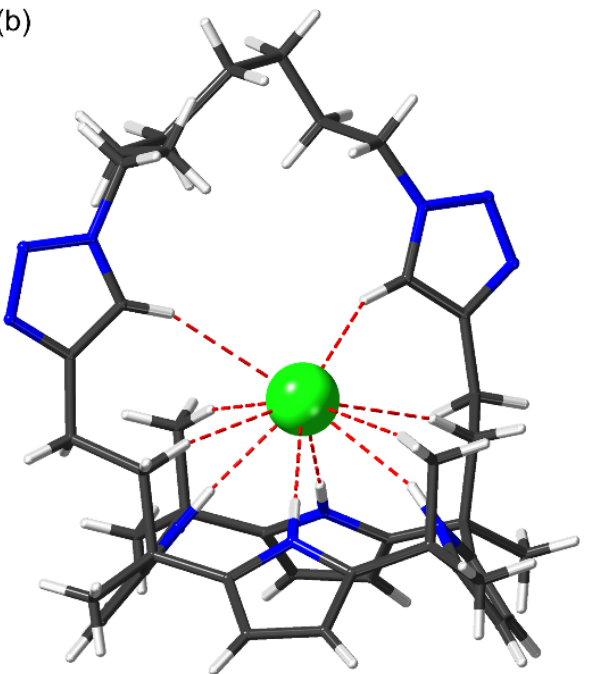

Fig. 4. Single crystal X-ray structures of $5 \cdot \mathrm{TBACl}$ (a) and $\mathbf{6} \cdot \mathrm{TBACl}$ (b) complexes. Minor orientation of the disordered atoms, TBA and DMSO are excluded for clarity. $\mathrm{NH}^{\cdots} \mathrm{Cl}^{-}$and $\mathrm{CH}^{\cdots} \mathrm{Cl}^{-}$hydrogen bonds are displayed as red dashed lines. Full crystallographic data can be found in the Supplementary Materials.

\section{Transmembrane anion transport studies}

The ability of the compounds to facilitate $\mathrm{Cl}^{-}$uniport and $\mathrm{H}^{+} / \mathrm{Cl}^{-}$symport was tested in a $\mathrm{KCl}$ cotransport assay with the addition of valinomycin (for $\mathrm{Cl}^{-}$uniport) and monensin (for $\mathrm{H}^{+} / \mathrm{Cl}^{-}$symport) as previously described,[9,15] with $\mathrm{Cl}^{-}$ efflux monitored by a $\mathrm{Cl}^{-}$ion selective electrode (ISE). $\mathrm{KCl}$ (300 mM) was used the internal medium and K-gluconate (300 mM) as the external medium. Here gluconate was used as an untransportable anion to prevent anion exchange. However, it should be noted that gluconate could potentially competitively bind to anion transporters without being transported and slow down anion transport as suggested by Moran et al.[16] In the valinomycin-coupled assay, the anion transporter facilitates $\mathrm{Cl}^{-}$uniport that coupled to valinomycin-facilitated $\mathrm{K}^{+}$uniport to give overall $\mathrm{KCl}$ transport (Figure 5). In the monensin-coupled assay, by contrast, the processs studied is the $\mathrm{H}^{+} / \mathrm{Cl}^{-}$symport facilitated by anion transporter with the resultant $\mathrm{pH}$ gradient dissipated by monensin-facilitated $\mathrm{K}^{+} / \mathrm{H}^{+}$antiport, leading to overall $\mathrm{KCl}$ transport. Both 5 and $\mathbf{6}$ show efficient $\mathrm{Cl}^{-}$uniport whereas only a minor amount of $\mathrm{H}^{+} / \mathrm{Cl}^{-}$symport at $2 \mu \mathrm{M}$ (or 2 mol\%, compound to lipid molar ratio), indicating that these compounds are selective for $\mathrm{Cl}^{-}$over $\mathrm{H}^{+} / \mathrm{OH}^{-}$. Control experimentals with 5 or $\mathbf{6}$ alone show no $\mathrm{Cl}^{-}$efflux, confirming that these compounds do not facilitate metal ion transport or non-specific membrane leakage (Fig. S25). Because of the poor $\mathrm{NO}_{3}{ }^{-}$transport activity of the strapped calixpyrroles, ${ }^{12 \mathrm{~b}}$ we did not employ the $\mathrm{Cl}^{-} / \mathrm{NO}_{3}{ }^{-}$exchange assay to charaterize these transporters. 


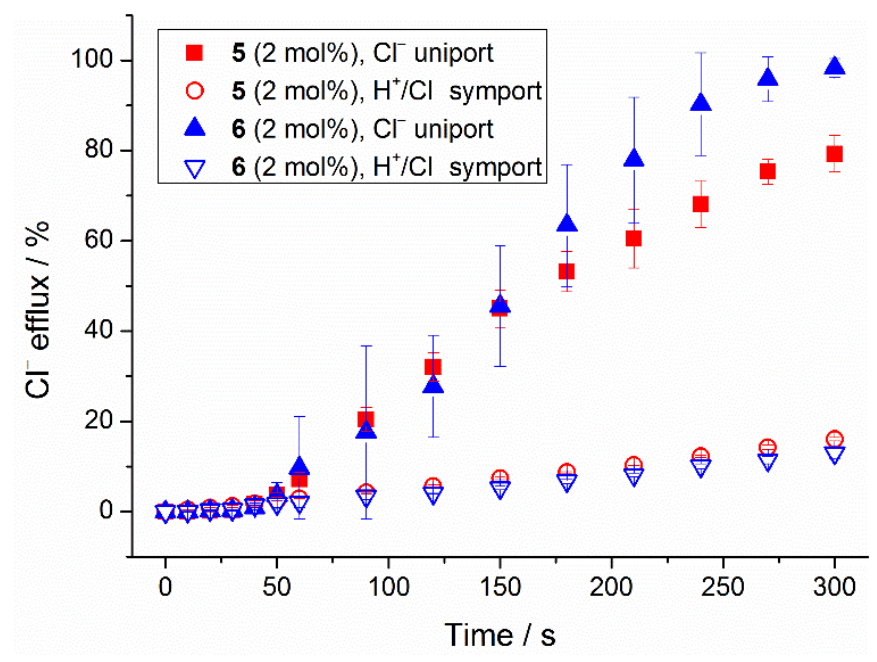

Fig. 5. $\mathrm{Cl}^{-}$uniport and $\mathrm{H}^{+} / \mathrm{Cl}^{-}$symport facilitated by compounds 5 and $\mathbf{6}$ (both tested at $2 \mu \mathrm{M}$ or 2 mol\% compound to lipid molar ratio), determined using an ISE assay using POPC vesicles in the presence of either valinomycin (for $\mathrm{Cl}^{-}$uniport) or monensin (for $\mathrm{H}^{+} / \mathrm{Cl}^{-}$symport). Error bars represent standard deviations from two or three repeats. Note the errors for compound are high presumably because of the tendency of this compound to precipitate from the aqueous solution when added to the lipid suspensions as DMSO solutions.

To quantify the $\mathrm{Cl}^{-}$uniport activity and $\mathrm{Cl}^{-}$over $\mathrm{H}^{+} / \mathrm{OH}^{-}$selectivity of the compounds 5 and $\mathbf{6}$, we performed a different assay, i.e. a modified HPTS assay[17] with $N$-methyl-D-glucamine chloride (NMDG-Cl) as the medium, which involved the use of gramicidin D (Gra or G) a naturally occurring proton channel, and oleic acid (OA)[9,15] as schematically illustrated in Fig. 6. The large hydrophilic cation $\mathrm{NMDG}^{+}$was used to prevent metal ion transport. The assay measures the rate of $\mathrm{pH}$ gradient dissipation induced by anion transporters or a combination of anion transporters and Gra facilitating $\mathrm{H}^{+} / \mathrm{Cl}^{-}$symport or $\mathrm{OH}^{-} / \mathrm{Cl}^{-}$antiport. Note that the thermodynamic driving forces and the amount of ion fluxes are different in the HPTS assay compared with the ISE assay. The transport process in the HPTS assay was driven by a $\mathrm{pH}$ gradient and required a $\mathrm{H}^{+}$and $\mathrm{Cl}^{-}$efflux (or an $\mathrm{OH}^{-}$influx and a $\mathrm{Cl}^{-}$efflux) of $5 \mathrm{mM}$ to reach equilibrium, whereas in the ISE assay, the transport was driven by a $\mathrm{Cl}^{-}$concentration gradient and required a $\mathrm{K}^{+}$and $\mathrm{Cl}^{-}$efflux of $300 \mathrm{mM}$ to reach equilibrium. In the absence of gramicidin $\mathrm{D}$, the assay determines the activity of the anion transporter in facilitating $\mathrm{H}^{+} / \mathrm{Cl}^{-}$or $\mathrm{OH}^{-} / \mathrm{Cl}^{-}$antiport, where the transport of $\mathrm{Cl}^{-}$or $\mathrm{H}^{+} / \mathrm{OH}^{-}$may be rate-limiting (Fig. 6a). Neutral hydrogen bond-based anion transporters are known to facilitate $\mathrm{H}^{+}$transport either by deprotonation of the hydrogen bond donors[9] or by a fatty acid shuttling mechanism.[10] For the latter mechanism, the process is fatty acid-dependent (Fig. 6c) and therefore the assay was also conducted with oleic acid added to the vesicles. In the presence of Gra that facilitates rapid $\mathrm{H}^{+}$uniport, the anion transporter only needs to faciliate $\mathrm{Cl}^{-}$uniport for dissipation of $\mathrm{pH}$ gradient (Fig. 6b). Therefore if the anion transporter is $\mathrm{Cl}^{-}>\mathrm{H}^{+} / \mathrm{OH}^{-}$selective, gramicidin would enhance the rate of $\mathrm{pH}$ gradient dissipation by replacing the rate-limiting step of $\mathrm{H}^{+} / \mathrm{OH}^{-}$transport, thus allowing the intrinsic $\mathrm{Cl}^{-}$uniport activity to be determined. 
(b)

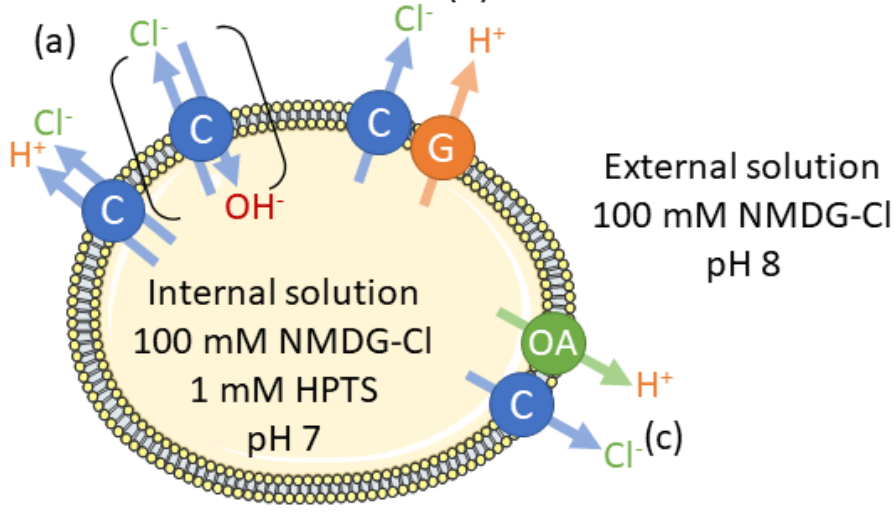

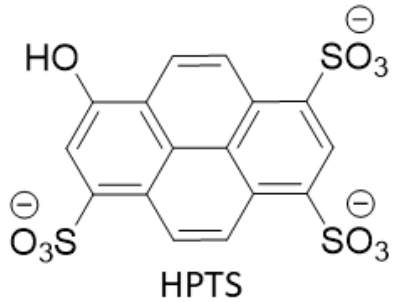

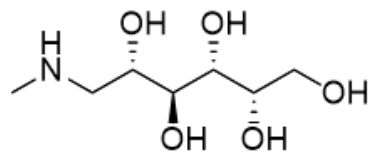

NMDG

Fig. 6. Overview of NMDG-Cl HPTS assay. Conditions- Internal: NMDG-Cl $100 \mathrm{mM}$ and HPTS $1 \mathrm{mM}$ buffered to $\mathrm{pH} 7$ with HEPES buffer $10 \mathrm{mM}$. External: NMDG-Cl $100 \mathrm{mM}$ buffered to $\mathrm{pH} 7$ with HEPES buffer $10 \mathrm{mM}$, pulse: NMDG to bring external $\mathrm{pH}$ to 8. The transport was initiated by addition of a DMSO solution of the transporter. (a) The transporter was added alone and the electroneutral $\left(\mathrm{H}^{+} / \mathrm{Cl}^{-}\right.$symport or $\mathrm{Cl}^{-} / \mathrm{OH}^{-}$antiport) transport was monitored by following the $\mathrm{pH}$ gradient dissipation. (b) Gramicidin (G) was added which facilitates $\mathrm{H}^{+}$transport, this will allow electrogenic $\mathrm{Cl}^{-}$transporters to function within the assay, the transport was monitored by following the $\mathrm{pH}$ gradient dissipation. (c) Oleic acid (OA) was added to evaluate the compounds ability to uphold selectivity in the presence of fatty acids.

Quantification of $\mathrm{Cl}^{-}$uniport acitivity and $\mathrm{Cl}^{-}>\mathrm{H}^{+} / \mathrm{OH}^{-}$selectivity and was undertaken by dose-dependent Hill analyses which afforded an effetive concentration to reach $50 \%$ of maximum transport at $200 \mathrm{~s}$ (EC 50 ) expressed as the transporter concentration or the transporter to lipid molar ratio, where a low EC $_{50}$ value indicates a high transport activity. To simplify the analysis, we examined the dependence of fluorescence intensity ratio between the basic and acidic forms of HPTS ( $\left.I_{\text {base }} / I_{\text {acid }}\right)$ on the amount of base added in the $\mathrm{pH}$ range of 7-8 after the vesicles were lysed with a detergent. The results (Fig. S26) demonstrate that $I_{\text {base }} / I_{\text {acid }}$ is approximately linear to the amount of base added, thus justifying the use of $I_{\text {base }} / I_{\text {acid }}$ to indicate the progress of $\mathrm{H}^{+}$efflux. The $\mathrm{EC}_{50}$ Gra value provides a measure of $\mathrm{Cl}^{-}$uniport activity as Gra removes the need for the anion transporter to facilitate the potentially rate-limiting $\mathrm{H}^{+}$transport. The ratio between $\mathrm{EC}_{50}$ values in the absence and presence of Gra gives a selectivity factor $\left(\mathrm{S}_{\mathrm{G}}\right)$ that quantifies $\mathrm{Cl}^{-}$over $\mathrm{H}^{+} / \mathrm{OH}^{-}$selectivity. The selectivity factor was additionally determined in the presence of oleic acid (SoA/G) to evaluate the $\mathrm{Cl}^{-}$over $\mathrm{H}^{+} / \mathrm{OH}^{-}$selectivity dependent on the fatty acid shuttling pathway. The $\mathrm{S}_{\mathrm{OA} / \mathrm{G}}$ value is more biologically relavent than $\mathrm{S}_{\mathrm{G}}$ because biological membranes contain signficant amounts of free fatty acids. The EC 50 and selectivity factors for 5 and $\mathbf{6}$ are summaried in Table 1, along with previously reported results for 2-4. We also performed an initial rate analysis at a fixed transporter concentration and the results are summarized in Table S1.

In the absence of fatty acids, compounds $\mathbf{5}$ and $\mathbf{6}$ show acceleration of pH gradient dissipation by Gra indicating high selectivity for $\mathrm{Cl}^{-}$over $\mathrm{H}^{+} / \mathrm{OH}^{-}$with $\mathrm{S}_{\mathrm{G}}$ values of 18, and 9.5, respectively. Remarkably, the EC $\mathrm{C}_{50}$ Gra values of 5 and 6 are substantially lower than previously reported shorter strapped compounds 2-4, demonstrating significantly improved $\mathrm{Cl}^{-}$uniport activities attributable to increased lipophilicity of $\mathbf{5}$ and $\mathbf{6}$ due to the extended alkyl linker length. However, 5 and $\mathbf{6}$ show modestly accelerated $\mathrm{H}^{+}$transport by oleic acid, leading to reduced $\mathrm{Cl}^{-}$over $\mathrm{H}^{+} / \mathrm{OH}^{-}$selectivity in the presence of oleic acid $\left(\mathrm{S}_{\mathrm{OA}} / \mathrm{G}\right)$. Previously the $\mathrm{Cl}^{-}$over $\mathrm{H}^{+} / \mathrm{OH}^{-}$selectivity of the shortest strapped compouds 2 and 3 were found to be unaffected by fatty acids (i.e. $\mathrm{S}_{\mathrm{OA} / \mathrm{G}} \approx \mathrm{S}_{\mathrm{G}}$ ), while that of $\mathbf{4}$ was slightly diminised by fatty acids (S $\mathrm{S}_{\mathrm{OA} / \mathrm{G}}$ $<\mathrm{S}_{\mathrm{G}}$ ).[12a] In the current work, fatty acid induced a more pronounced attenutaion of $\mathrm{Cl}^{-}$over $\mathrm{H}^{+} / \mathrm{OH}^{-}$selectivity for the longest strapped compounds $\mathbf{5}$ and $\mathbf{6}$, thus supporting the hypothesis that expanding the size of the anion binding cavity to some extent favors the binding and transport of carboxylate ions over the smaller $\mathrm{Cl}^{-}$ions. Despite the compromised selectivity for the longer straps, the strapped calixpyrroles still represents the class of compounds with the highest $\mathrm{Cl}^{-}$ 
over $\mathrm{H}^{+} / \mathrm{OH}^{-}$selectivity to date that can resist $\mathrm{H}^{+}$transport via the fatty acid shuttling mechanism due to threedimensional encapsulation of chloride (Fig. 4.). Note that the Hill coefficients ( $n$ values) are higher than 1 in many cases which can be attributed to ion transport by an aggregated (transporter) ${ }_{n} \cdot$ ion species.

Table $1 \quad$ Summary of $\mathrm{Cl}^{-}$transport activity and selectivity over $\mathrm{H}^{+} / \mathrm{OH}^{-}$for 2-6.

\begin{tabular}{|c|c|c|c|c|c|c|c|c|}
\hline Compound & Compound alone & & with Gra ${ }^{a}$ & & $\mathrm{~S}_{\mathrm{G}}^{\mathrm{b}}$ & with $\mathrm{OA}^{\mathrm{c}}$ & & ${\mathrm{SOA} / \mathrm{G}^{\mathrm{d}}}^{\mathrm{d}}$ \\
\hline & $\mathrm{EC}_{50} / \mu \mathrm{M}(\mathrm{mol} \%)$ & $n^{\mathrm{e}}$ & $\mathrm{EC}_{50} / \mu \mathrm{M}(\mathrm{mol} \%)$ & $n^{\mathrm{e}}$ & & $\mathrm{EC} 50 \mathrm{OA} / \mu \mathrm{M}(\mathrm{mol} \%)$ & $n$ & \\
\hline $2^{f}$ & $11 \pm 0$ & $2.9 \pm 0.2$ & $0.60 \pm 0.03$ & $1.7 \pm 0.2$ & 18 & $11 \pm 0$ & $2.3 \pm 0.2$ & 18 \\
\hline $3^{f}$ & $4.1 \pm 0.1$ & $3.8 \pm 0.5$ & $0.38 \pm 0.03$ & $1.3 \pm 0.1$ & 11 & $3.6 \pm 0.0$ & $4.1 \pm 0.2$ & 9.5 \\
\hline $4^{f}$ & $2.7 \pm 0.0$ & $4.5 \pm 0.3$ & $0.18 \pm 0.01$ & $1.0 \pm 0.0$ & 15 & $1.6 \pm 0.1$ & $1.8 \pm 0.2$ & 8.9 \\
\hline 5 & $1.5 \pm 0.1$ & $2.0 \pm 0.3$ & $0.092 \pm 0.004$ & $1.4 \pm 0.1$ & 16 & $0.43 \pm 0.03$ & $1.6 \pm 0.1$ & 4.7 \\
\hline 6 & $1.1 \pm 0.0$ & $2.3 \pm 0.2$ & $0.15 \pm 0.01$ & $1.2 \pm 0.1$ & 7.0 & $0.49 \pm 0.03$ & $1.7 \pm 0.2$ & 3.3 \\
\hline
\end{tabular}

Notes: a Hill analysis in the presence of gramicidin D; this value shows the total $\mathrm{H}^{+} / \mathrm{Cl}^{-}$symport $\left(\mathrm{Cl}^{-} / \mathrm{OH}^{-}\right.$antiport) activity possible, with no rate-limiting $\mathrm{H}^{+} / \mathrm{OH}^{-}$transport. The Gra concentration has been optimised at $0.1 \mu \mathrm{M}$ to prevent this having a limiting effect. ${ }^{b}$ $\mathrm{Cl}^{-}$over $\mathrm{H}^{+} / \mathrm{OH}^{-}$selectivity factor $\mathrm{S}_{\mathrm{G}}$ is calculated by dividing EC50 in the absence of Gra by the EC50 Gra. $\mathrm{S}_{\mathrm{G}}>1$ indicates $\mathrm{Cl}^{-}$selectivity. ${ }^{\mathrm{c}}$ Hill analysis in the presence of oleic acid $(2 \mu \mathrm{M})$; this value shows the effect of fatty acids on the selectivity. ${ }^{\mathrm{d}} \mathrm{Cl}^{-}$ over $\mathrm{H}^{+} / \mathrm{OH}^{-}$selectivity value in the presence of oleic acid, calculated by dividing the EC ${ }_{50}$ OA by the EC 50 Gra. SOA/G $>1$ indicates $\mathrm{Cl}^{-}$selectivity. ${ }^{\text {e }}$ Hill coefficients determined by the Hill analysis. The Hill coefficient indicates the stoichiometry of the receptoranion eomplex formed to facilitate anion tranport. ${ }^{\mathrm{f}}$ Values for previous reported compounds are taken from [12a]. ${ }^{\mathrm{g}}$ Errors in this table are statistical errors of fitting.

\section{CONCLUSION}

Based on our previous work on selective halide transport facilitated by strapped calixpyrroles, we have synthesized strap-extended calixpyrroles $\mathbf{5}$ and $\mathbf{6}$ featuring three-dimentional encapsulation of chloride ions via multiple $\mathrm{NH}$ and $\mathrm{CH}$ hydrogen bond interactions as confirmed by solid-state analysis. Extension of the alkyl linker led to improved $\mathrm{Cl}^{-}$ uniport activity but compromised $\mathrm{Cl}^{-}$over $\mathrm{H}^{+} / \mathrm{OH}^{-}$selectivity due to the larger anion binding cavity facilitating binding and transport of deprotonated fatty acids. The structure-selectivity relationship demonstrated in this work is informative for future development of highly active and selective $\mathrm{Cl}^{-}$uniporters for channel replacement therapies where $\mathrm{H}^{+}$ transport leading to $\mathrm{pH}$ disruption and autophagy inhibition should be avoided.

General experimental details, synthetic procedures, NMR spectra and titration, data, further details of the crystallography and anion transport assays (FIGS S1-S32 and Table S1) are given in the supplementary material. This material is available free of charge via the Internet at http://www.worldscinet.com/jpp/jpp.shtml. 
We thank the ARC for funding (DP 180100612), the EPSRC for a DTP studentship (HJC), for access to the crystallographic facilities at the University of Southampton and for EPSRC Core Capability Funding (EP/K039466/1).

\section{REFERENCES}

(1) (a) Li H, Valkenier H, Thorne AG, Dias CM, Cooper JA, Kieffer M, Busschaert N, Gale PA, Sheppard DN and Davis AP. Chem. Sci. 2019; DOI:10.1039/c9sc04242c; (b) Gale PA, Davis JT and Quesada R. Chem. Soc. Rev. 2017; 46: 2497-2519; (c) Haynes CJE and Gale PA. Chem. Commun. 2011: 8203-8209.

(2) (a) Gale PA, Light ME, McNally B, Navakhun K, Sliwinski KE and Smith BD. Chem. Commun. 2005: 3773-3775; Jowett LA, Howe ENW, Soto-Cerrato V, Van Rossom W, Pérez-Tomás R and Gale PA. Sci. Rep. 2017; 7: 9397.

(3) Hernandez PI, Moreno D, Javier AA, Torroba T, Pérez-Tomás R and Quesada R. Chem. Commun. 2012; 48: 15561558.

(4) Busschaert N, Wenzel M, Light ME, Iglesias-Hernández P, Pérez-Tomás R and Gale PA. J. Am. Chem. Soc. 2011; 133: $14136-14148$.

(5) Moore SJ, Haynes CJE, González J, Sutton JL, Brooks SJ, Light ME, Herniman J, Langley GJ, Soto-Cerrato V, Pérez-Tomás R, Marques I, Costa PJ, Felix V and Gale, PA. Chem. Sci. 2013; 4: 103-117.

(6) Busschaert N, Kirby IL, Young S, Coles SJ, Horton PN, Light ME and Gale PA. Angew. Chem., Int. Ed. 2012; 51: 4426-4430.

(7) Sato T, Konno H, Tanaka Y, Kataoka T, Nagai K, Wasserman HH and Ohkuma S J. Biol. Chem. 1998; 273: 2145521462.

(8) (a) Park S-H, Park S-H, Howe ENW, Hyun JY, Chen LJ, Huang I, Vargas-Zuñiga G, Busschaert N, Gale PA, Sessler JL and Shin I. Chem 2019; 5: 1210-1222; (b) Zhang Z, Wang Y, Xie W, Howe ENW, Busschaert N, Sauvat A, Leduc M, Gomes-da-Silva LC, Chen G, Martins I, Deng X, Maiuri L, Kepp O, Soussi T, Gale PA, Zamzami N and Kroemer G. Cell Death \& Disease 2019; 10:242 (c) Busschaert N, Park S-H, Baek K-H, Choi YP, Park J, Howe ENW, Hiscock JR, Karagiannidis LE, Marques I, Félix V, Namkung W, Sessler JL, Gale PA, and Shin I. Nat. Chem. 2017; 9: 667-675; (d) Rodilla AM, Korrodi-Gregório L, Hernando E, Manuel-Manresa P, Quesada R, Pérez-Tomás R and Soto-Cerrato V. Biochem. Pharmacol. 2017; 126: 23-33.

(9) (a) Wu X, Judd LW, Howe ENW, Withecombe AM, Soto-Cerrato V, Li H, Busschaert N, Valkenier H, PérezTomás R, Sheppard DN, Jiang Y-B, Davis AP and Gale PA. Chem 2016; 1: 127-146; (b) Wu X, Small JR, Cataldo A, Withecombe AM, Turner P and Gale PA. Angew. Chem. Int. Ed. 2019; 58: 15142-15147.

(10) (a) Wu X and Gale PA. J. Am. Chem. Soc. 2016; 138: 16508-16514; see also (b) Howe ENW and Gale PA. J. Am. Chem. Soc. 2019; 141: 10654-10660.

(11) Jowett LA, Ricci A, Wu X, Howe ENW and Gale PA. Molecules 2019; 24: 1278.

(12) (a) Clarke HJ, Howe ENW, Wu X Sommer F, Yano M, Light ME, Kubik S and Gale, PA. J. Am. Chem. Soc. 2016; 138: 16515-16522; (b) Yano M, Tong CC, Light ME, Schmidtchen FP and Gale PA. Org, Biomol. Chem. 2010; 8: 4356-4363.

(13) Dabrowa K, Ulatowski F, Lichosyt D and Jurczak J. Org. Biomol. Chem. 2017; 15: 5927-5943.

(14) Thordarson P. in Supramolecular Chemistry: from Molecules to Nanomaterials; Gale PA and Steed JW Editors; John Wiley \& Sons, Ltd: 2012.

(15) Wu X, Howe ENW and Gale PA. Acc. Chem. Res. 2018; 51: 1870-1879.

(16) Fiore M, Cossu C, Capurro V, Picco C, Ludovico A, Mielczarek M, Carreira-Barral I, Caci E, Baroni D, Quesada R and Moran, O. Brit. J. Pharmacol. 2019; 176: 1764-1779 
(17) Matile S and Sakai N. in Analytical Methods in Supramolecular Chemistry; Schalley, CA, Editor; Wiley-VCH: Weinheim, 2012, pp711-742. 